\title{
Adjuvant Coil Assisted Glue Embolization of Vein of Galen Aneurysmal Malformation in Pediatric Patients
}

\author{
Dong Joon Kim, MD, PhD', Dae Chul Suh, MD², \\ Byung Moon Kim, MD', Dong Ik Kim, MD, PhD ${ }^{1,3}$
}

Purpose: Adjuvant coils may offer advantages in flow control during glue embolization of high flow vein of Galen aneurysmal malformation (VGAM) patients but involves specific issues such as feasibility, durability and coil mass effect. The purpose of this study is to assess the outcome of adjuvant coils in addition to transarterial glue embolization for treatment of these patients.

Materials and Methods: Five pediatric VGAM patients (age range; 11 weeks to 2 yrs 2 mos) with high flow fistulous angioarchitecture were treated with adjuvant coils 1 ) in the distal feeding artery and/or 2) in the vein of Galen followed by glue embolization of the shunt. The angiographic / clinical outcomes were assessed.

Results: Adjuvant coils were deployed in the distal feeding artery $(n=3)$, vein of Galen pouch plus distal feeding artery $(n=2)$. Additional transarterial glue embolization of the fistulae was successfully performed $(n=4)$. Complete occlusion was achieved with coils in one case. Complete occlusion was achieved for all mural type cases $(n=4)$. Residual feeders remained in a case of choroidal type of VGAM. No complications were noted related to the treatment. All patients showed normal development on follow up (range: 7.6 to 88.8 mo, mean $49.3 \mathrm{mo}$ ). Initial hydrocephalus improved on follow up despite coil mass effect in dilated vein of Galen.

Conclusion: Adjuvant coils for flow control with glue embolization may be a safe and effective treatment method for VGAM patients with high flow fistulous feeders.

Key Words : Coil; Embolization; Glue; Vein of Galen aneurysmal malformation

\footnotetext{
'Department of Radiology, Yonsei University College of Medicine, Seoul, Korea

2Department of Radiology, University of Ulsan, College of Medicine, Asan Medical Center, Seoul, Korea

${ }^{3}$ Department of Radiology, CHA University School of Medicine, CHA Bundang Medical Center, Seongnam, Korea

This work was supported by a faculty research grant of Yonsei University College of Medicine (6-2015-0022, Dong Joon Kim).

Received February 8, 2018; Revised February 16, 2018; Accepted February 19, 2018

Correspondence to: Dong Joon Kim, MD, PhD

Department of Radiology, Yonsei University College of Medicine, 50-1 Yonsei-ro, Seodaemun-gu, Seoul 03722, Korea.

Tel. +82.2.2228.7400 Fax.+82.2.393.3035 E-mail: djkimmd@yuhs.ac

This is an Open Access article distributed under the terms of the Creative Commons Attribution Non-Commercial License (http://creativecommons.org/licenses/by-nc/3.0) which permits unrestricted non-commercial use, distribution, and reproduction in any medium, provided the original work is properly cited.
} 


\section{Dong Joon Kim, et al.}

Vein of Galen aneurysmal malformation (VGAM) is a rare arteriovenous malformation of the choroidal system draining into the median vein of prosencephalon, the embryonic precursor of the vein of Galen. ${ }^{1,2}$ Results of microsurgical treatment of VGAM are dismal with reported mortality rate of $84.6 \%{ }^{3}$ Thus endovascular embolization is the preferred treatment of choice..$^{1,3-5}$ Transarterial embolization of the fistula is often performed with liquid embolic agents such as glue. ${ }^{1}$ Recent reports show successful use of onyx. ${ }^{6,7}$ However, challenges in using these liquid embolic agents remain especially in patients with angioarchitectural features such as large high flow fistulae. ${ }^{8}$ Adjuvant detachable coils in addition to glue embolization have been used for flow control in vascular lesions of the body with high flow fistula.$^{8-13}$ Combined transarterial/transvenous methods have been used successfully for approaching the target fistula in VGAM patients. ${ }^{12}$ But specific issues related to this method such as the coil embolization methods, durability of treatment, effects of persistent coil mass, treatment of residual feeders, and potential complications in VGAM patients are limited. ${ }^{3,9,12,14}$ The purpose of this study is to assess the feasibility and outcome of adjuvant coil assisted glue embolization in treatment of these VGAM patients with high flow fistulae.

\section{MATERIALS AND METHODS}

Pediatric patients who were treated for VGAM were collected. Among the VGAM patients, five consecutive patients ( $\mathrm{M}: \mathrm{F}=3: 2$, age range; 11 weeks to 2 yrs 2 mos) in whom coils were used for flow control for high flow fistulae were included. The initial treatment results, follow up angiographic/imaging findings, and clinical follow up results were assessed.

For each patient, the clinical status and the radiological findings were carefully examined for the optimal timing of the endovascular treatment. The MR and/or CT images were examined to assess the individual angioarchitecture prior to treatment. The procedure was performed under general anesthesia. In general, a 4Fr sheath was used to access the femoral artery. A $4 \mathrm{Fr}$ catheter was used for angiography of the internal carotid and vertebral arteries. The angiographic features of the feeders, shunt location, and venous outflow patterns were carefully examined. The feeders were assessed for either high flow fistula or nidus like feeders. The location of the shunt was assessed in regard to the feeders. The draining veins were assessed for the dilated vein of Galen, presence of deep venous drainage, and outflow restrictions. When a high flow fistula was identified, a microcatheter was selected as distally as possible in the feeding artery. Two main methods were used for deploying adjuvant coils: Detachable coils were mainly deployed in the 1) distal segment of the feeding artery, or 2) in the vein of Galen for flow reduction and as a scaffold for stable coil deployment in the distal feeding artery. When the coils were deployed in the dilated vein of Galen, the intent was not to completely occlude the shunt but to reduce flow, thus was incompletely packed. For the distal artery, detachable coil diameter 0.5 to $1 \mathrm{~mm}$ larger than the vessel diameter was chosen. For the dilated vein of Galen, coil diameter corresponding to the diameter of the vessel was chosen. After flow reduction with the coils, the distal feeder was embolized with glue (nbutyl cyanoacrylate). The concentration of glue was decided at the discretion of the operator. The patients were followed in the intensive care unit immediately after the procedure for at least 24 hours. Cross sectional imaging was performed within a few days.

After discharge, the patients were followed regularly in the outpatient clinic with special attention to developmental milestones. Patients with delay in development were referred for rehabilitation therapy. MRI and MR angiography follow up was performed regularly on a three month to yearly basis for assessment of brain parenchymal changes including hydrocephalus and recurrence/residual feeders. Institutional review board approval was obtained with waiver of informed consent based on the retrospective study design.

\section{RESULTS}

The characteristics of the lesions are summarized in Table 1. The gross classification of the vein of Galen aneurysmal shunt lesions were mural type VGAM $(n=4)$ and choroidal type VGAM $(n=1)$. The mural type VGAM consisted of one to three large fistulous feeders (cases 1,2,3,5). The choroidal type VGAM consisted of multiple nidal type of feeders (case 4).

\section{Transarterial embolizations}

All treatment was performed by transarterial access. The vein of Galen was approached transarterially across the large high flow fistula. Transarterial glue embolization of the high flow fistula was successfully performed in all cases after flow reduction with the adjuvant coil deployment.

For the mural type lesions, adjuvant coils were 


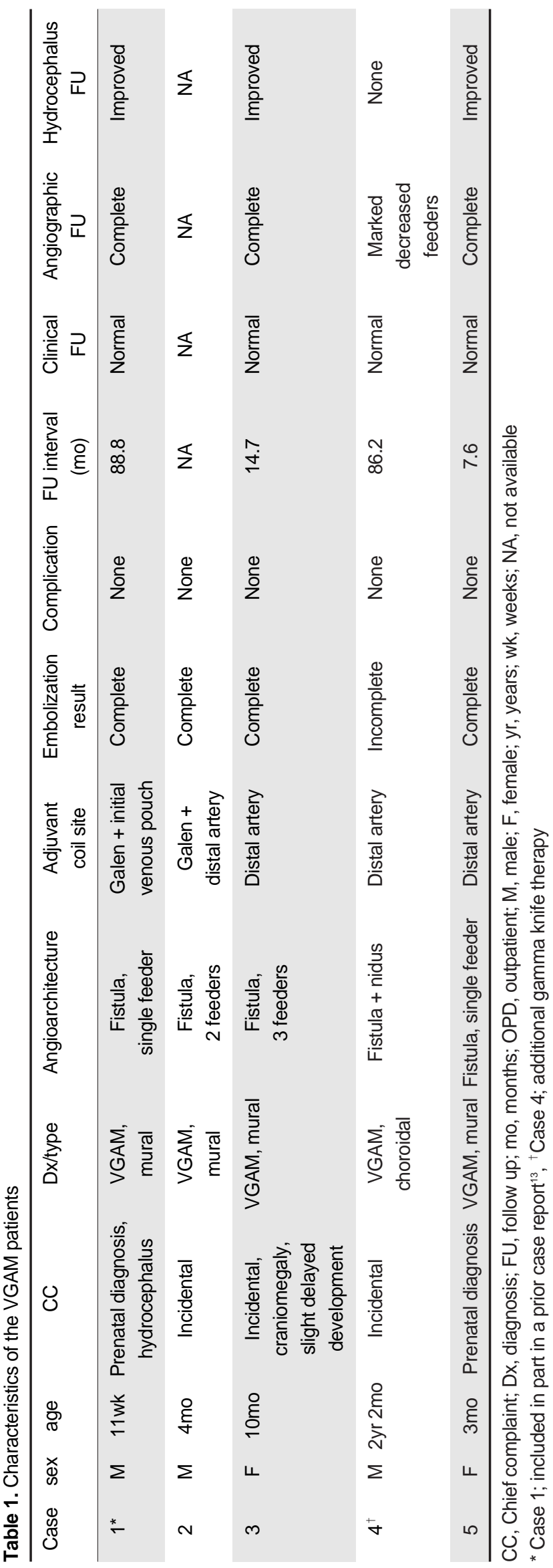

deployed in the distal artery $(\mathrm{n}=2)$ and vein of Galen plus distal artery/proximal venous pouch $(n=2)$ (Fig. 1). Complete occlusion was achieved for mural type cases with occlusion of all high flow fistulae in the first session (cases 1, 2, 3, 5). Complete occlusion was achieved in a case (case 1) with only coil embolization of the vein of Galen plus focal proximal venous outpouch. However, recurrence of the shunt was detected on the three months follow up with aggravated hydrocephalus. The recurred fistula was completely embolized with glue in the second session. Complete occlusion was achieved in a case (case 5) with only coil embolization of the distal feeding artery.

For the choroidal type VGAM, adjuvant coils were deployed in the distal artery $(n=1)$ of the high flow fistulous feeder (Fig. 1). Residual nidal type of feeders remained after the embolization in this case (case 4). Due to difficulty of endovascular access of the residual feeders, two sessions of gamma knife treatment were performed for the residual shunt.

No complications were noted associated with the endovascular treatment in all cases.

\section{Follow up}

Follow up was available in four patients (7.6 to 88.8 mo, mean $49.3 \mathrm{mo}$ ). A single patient referred from a foreign country who had complete occlusion of the mural type shunt was lost to follow up (case 2). None of the other patients who had complete occlusion showed recanalization on follow up (cases 1, 3, 5). Post gamma knife treatment follow up showed progressive obliteration of the feeders (case 4).

Improvement of hydrocephalus was seen in the patients who initially presented with hydrocephalus (cases 1,3,5). This included a patient who was treated by adjuvant coils deployed in the dilated vein of Galen thus had persistence of coil mass effect (Fig. 2, case 1). No other brain parenchymal changes related to the coil mass were seen. Clinically, all patients showed normal development.

\section{DISCUSSION}

Our experience of adjuvant coil assisted glue embolization in treatment of pediatric VGAM patients with high flow fistulae show that this is a feasible treatment option especially for mural type of lesions with few arterial feeders. Flow control with coils allowed easier and safer glue embolization of the high flow fistula with good long term results.

The main goal of treatment in VGAM patients is to 


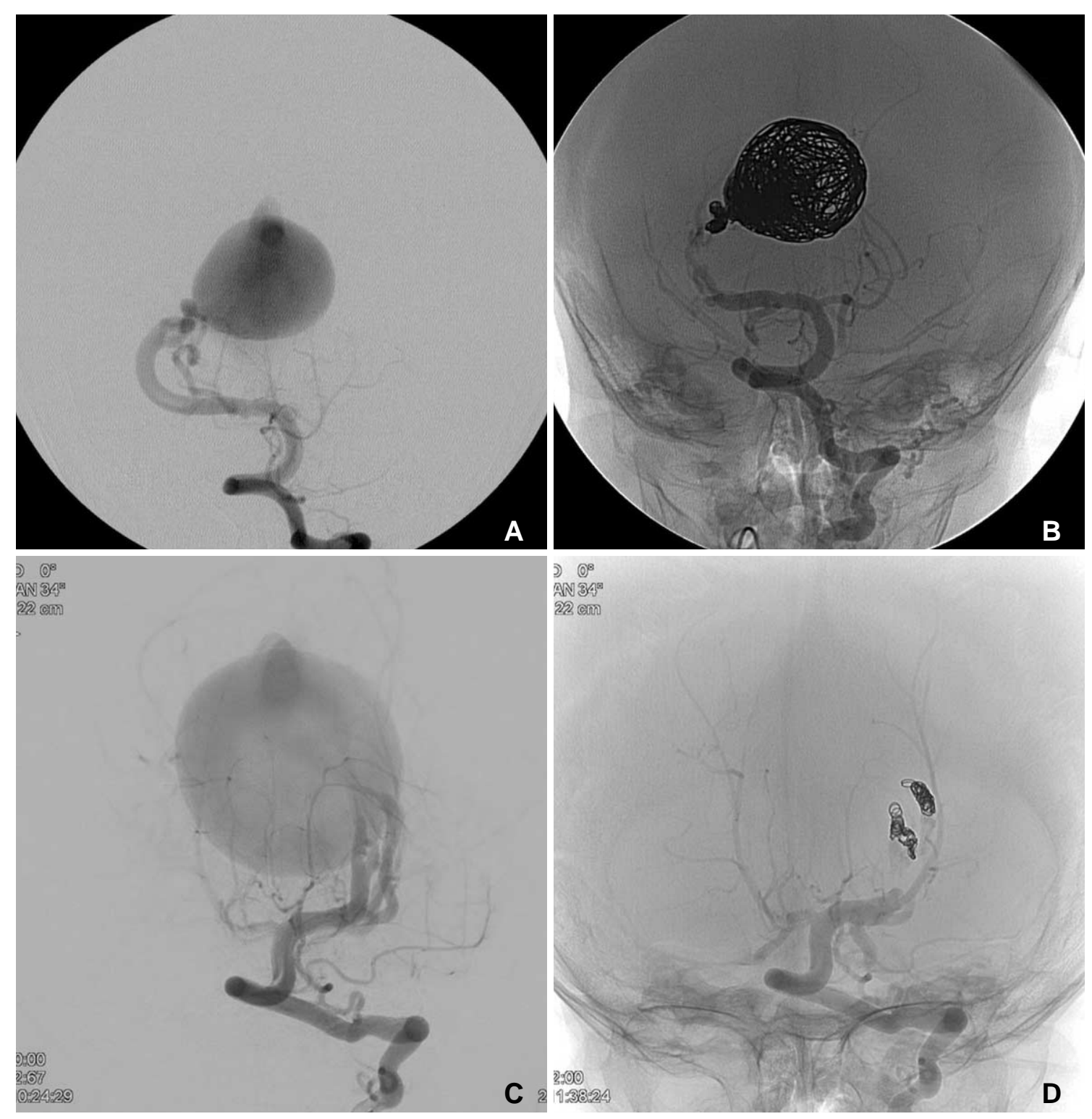

Fig. 1. Pre (A, C) and post (B, D) adjuvant coil assisted glue embolization of 2 cases of mural type VGAMs (AP views). Case 2 (A, B); 4 month year old male was referred for VGAM. The angiography showed a VGAM with 2 high flow fistulae. Due to the high flow, coils were deployed in the enlarged vein of Galen followed by coils in the distal feeding arteries. Additional glue embolization resulted in complete occlusion of the shunt. Case 3 (C, D); A 10-month old girl was referred for incidental findings of craniomegaly and slight delayed development. MR (not shown) and DSA showed a VGAM with three high flow fistulae. Detachable coils were successfully deployed at the distal aspect of the feeding arteries. Additional glue embolization occluding the fistulous point resulted in complete occlusion.

restore normal growth and development without neurological deficits by careful and timely management. ${ }^{1,15}$ Endovascular treatment is the preferred treatment modality with the fistulous zone as the target of treatment. ${ }^{1,3,5}$ However, flow control in patients with high flow fistula during injection of liquid embolic agents is often a challenge. Controlled occlusion of the target lesion site is often precluded due to the tendency of the embolic material to migrate distally with the fast flow. Use of high concentration glue with tantalum powder - which is not available in some countries - for radioopacity and lowering the blood pressure during the injection of glue may be adjunctive maneuvers for flow control. ${ }^{1}$ However, these maneuvers may not be sufficient in preventing potentially hazardous distal migration. In this regard, adjuvant coil embolization is an attractive option for flow control in patients with high flow shunt. 


\section{Coil Assisted Glue Embolization of VGAM}

\section{Treatment method and durability}

The main endovascular treatment target site is the distal feeding artery and the initial vein at the fistulous zone. ${ }^{1}$ Detachable coils are easier to control than the liquid embolic materials at the site of high flow fistulae. Thus, two main methods were used for our adjuvant coiling in our series according to the individual angioarchitecture of the patient. The coils were deployed at the farthest distal feeding artery or the vein of Galen plus distal feeding. With the deployment of coils in the distal artery, lower concentration of glue could be used with easier flow control. ${ }^{9,11}$ We did not experience any case of significant glue migration beyond the coils. The coil density necessary to achieve sufficient flow reduction for safe glue injection is difficult to determine. However, complete or near complete arrest of flow on test contrast injections was not necessary since the coils were much more effective in preventing distal migration of glue compared to contrast due to its viscosity.

Meila et al. reported their experience of flow occlusion using coils by a combined tranvenous and transarterial kissing microcatheter approach. They showed that by using the kissing microcatheter technique, they were successful in achieving complete or $>90 \%$ closure of the shunt in 11 of their 14 patients. ${ }^{12}$ This may be a good option when the microcatheter cannot approach or the coils cannot be safely deployed at the point of fistula. The deployment of coils in the fistulous zone may completely occlude the flow. ${ }^{10,12,16}$ Complete occlusion with only coils was achieved in the initial treatment in two of our cases (cases $1 \& 5$ ).
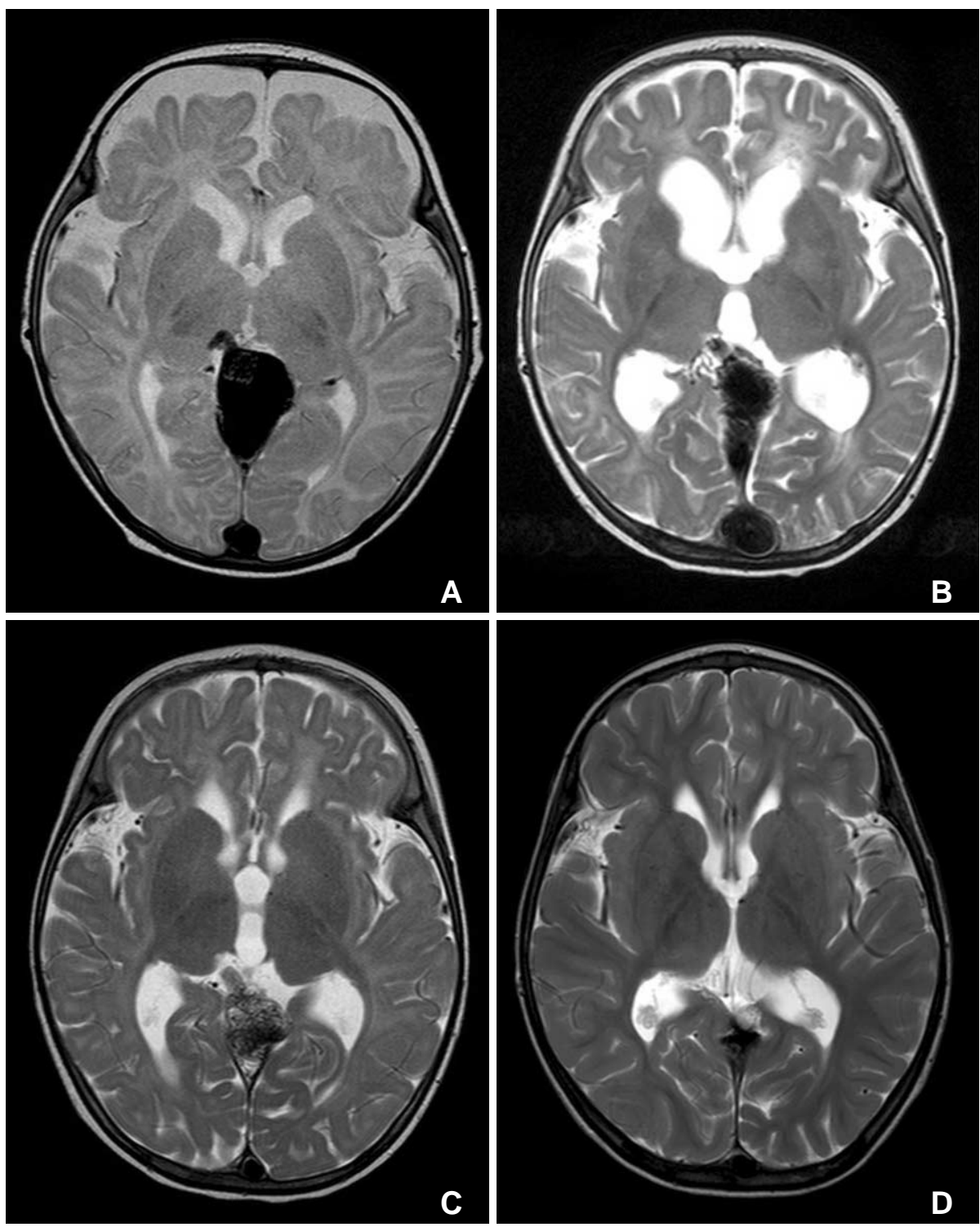

Fig. 2. Case 1: Reversible changes of hydrocephalus in accordance with reopening and occlusion of the VGAM shunt. MR T2 weighted image taken two days after the initial coil embolization of the dilated vein of Galen and the proximal venous pouch show mild hydrocephalus. Glue was not used due to complete occlusion of the shunt with the coils $(\mathbf{A})$. Three months follow up showed aggravation of hydrocephalus which prompted a repeat DSA revealing reopening of the previously coil embolized feeding artery (B). Second stage embolization was performed with additional adjuvant coils in the distal feeder and glue embolization. Complete occlusion was achieved. Six months follow up after the second stage embolization show marked improvement of the hydrocephalus despite the persistent mass effect in the dilated vein of Galen (C). Five years follow up show no signs of hydrocephalus (D). The patient is clinically normal on seven years follow up. 
However, durable complete occlusion with only coils was seen in only one of our cases (case 5). Recurrence due to insufficient penetration of the coils and glue in the distal feeder and the initial vein may result in recurrence as seen in 1 of our cases (case 1). ${ }^{8,13}$ The lesion recurred on follow up from migration of the coil mass into the vein of Galen. No recurrences were seen when adjuvant coils with sufficient glue cast occluded the distal feeder and the fistulous point.

\section{Persistent coil mass effect}

The cause of hydrocephalus in VGAM patients is controversial. The compressive effects of the enlarged vein of Galen on the cerebral aqueduct may cause noncommunicating hydrocephalus. ${ }^{8}$ Another cause may be the increased venous pressure in the venous sinuses from the arteriovenous (AV) shunt precluding cerebrospinal fluid absorption. ${ }^{1}$

In our series, improvement of hydrocephalus was seen in all patients treated with adjuvant coils in the distal artery and/or the dilated vein of Galen. Persistence of mass effect after coil deployment in the enlarged vein of Galen regarding the outcome of hydrocephalus is a valid concern. The explicit aggravation/improvement of hydrocephalus in accordance with the recurrence/occlusion of AV shunt in our case suggest that the increased venous pressure from the AV shunt may be the prominent pathogenesis of hydrocephalus in VGAM patients (Case 1, Fig. 2). Mild hydrocephalus which was present immediately after the initial coil embolization of the vein of Galen showed aggravation on the three months follow up concurrent with reopening of the shunt. Six month follow up after complete occlusion with additional adjuvant coil and glue embolization showed improvement of the hydrocephalus despite the persistence of mass effect in the enlarged vein of Galen.

\section{Residual shunt feeders}

Residual smaller feeders may remain after embolization of the main high flow fistula for choroidal type of lesions. These residual lesions may be treated by transarterial embolization in a staged session with regards to the patient's clinical status. ${ }^{1,8}$ Gamma knife therapy was performed in our case with residual nidus like feeders which were not amenable with transarterial embolization. Only a few reports of treatment of VGAM with gamma knife are available in the literature with mixed results. ${ }^{17-19}$ Marked decrease of residual feeders was seen after two sessions of gamma knife therapy suggesting a somewhat delayed response.
Although gamma knife therapy may be a treatment option, this should be limited to clinically stable patients who are not feasible for treatment with endovascular methods.

\section{Potential complications}

Coil embolization of the distal artery may be innocuous since no drainage routes are compromised. However, complete coil embolization of the vein of Galen may result in hemorrhage. ${ }^{8,20}$ Classically, the deep venous drainage is not known to be connected to the vein of Galen but exceptions are reported. . $^{2,21,22}$ Impairment of deep venous drainage or sudden congestion of subependymal anastomoses may cause hemorrhage in cases of complete venous occlusion with residual arterial feeders. ${ }^{1,8,14,20}$ Thus, our intention was not to completely occlude the vein when coils were introduced into the vein of Galen but only to provide a scaffold for coil deployment in the distal feeder artery.

Rupture of the feeding artery may be a concern during delivery of the coil. ${ }^{8}$ Fortunately, this was not encountered in our experience. Careful sizing and deployment of the coils are mandated.

This series is limited by the small number of cases thus caution is needed in interpreting the results. Due to the rarity of the disease, only a few large case series are available. Larger case series with longer follow up is warranted.

\section{CONCLUSION}

Our results show that adjuvant coils for flow control with glue embolization may be an effective method for safer and easier treatment of VGAM patients with high flow fistula. This method may be most effective when complete occlusion of the distal artery and the fistulous point is achieved and in mural type VGAMs with limited number of feeders.

\section{References}

1. Lasjaunias PL, Chng SM, Sachet M, Alvarez H, Rodesch G, Garcia-Monaco R. The management of vein of galen aneurysmal malformations. Neurosurgery 2006;59:S184-194; discussion S183-113

2. Lasjaunias P, Ter Brugge K, Berenstein A. Surgical neuroangiography: Clinical and interventional aspects in children, 2nd ed, Berlin Heidelberg: Springer-Verlag; 2006.

3. Khullar D, Andeejani AM, Bulsara KR. Evolution of treatment options for vein of galen malformations. J Neurosurg Pediatr 2010;6:444-451

4. Berenstein A, Fifi JT, Niimi Y, Presti S, Ortiz R, Ghatan S, et al. 


\section{Coil Assisted Glue Embolization of VGAM}

Vein of Galen malformations in neonates: new management paradigms for improving outcomes. Neurosurgery 2012;70:12071213; discussion 1213-1204

5. Moon JH, Cho WS, Kang HS, Kim JE, Lee SJ, Han MH. Vein of galen aneurysmal malformation: endovascular management of 6 cases in a single institute. J Korean Neurosurg Soc 2011;50:191194

6. Thiex R, Williams A, Smith E, Scott RM, Orbach DB. The use of onyx for embolization of central nervous system arteriovenous lesions in pediatric patients. AJNR Am J Neuroradiol 2010;31: $112-120$

7. Germanwala AV, Vora NA, Thomas AJ, Jovin T, Gologorsky Y, Horowitz MB. Ethylenevinylalcohol copolymer (onyx-18) used in endovascular treatment of vein of galen malformation. Childs Nerv Syst 2008;24:135-138

8. Pearl M, Gomez J, Gregg L, Gailloud P. Endovascular management of vein of galen aneurysmal malformations. Influence of the normal venous drainage on the choice of a treatment strategy. Childs Nerv Syst 2010;26:1367-1379

9. Mitchell PJ, Rosenfeld JV, Dargaville P, Loughnan P, Ditchfield MR, Frawley G, et al. Endovascular management of vein of galen aneurysmal malformations presenting in the neonatal period. AJNR Am J Neuroradiol 2001;22:1403-1409

10. Kong JC, Cheng KM, Cheung YL, Chan CM. Transarterial embolisation with guglielmi detachable coils in an infant with a vein of galen aneurysmal malformation. Hong Kong Med J 2012; $18: 435-438$

11. Heuer GG, Gabel B, Beslow LA, Stiefel MF, Schwartz ES, Storm PB, et al. Diagnosis and treatment of vein of galen aneurysmal malformations. Childs Nerv Syst 2010;26:879-887

12. Meila D, Hannak R, Feldkamp A, Schlunz-Hendann M, Mangold A, Jacobs $C$, et al. Vein of galen aneurysmal malformation: Combined transvenous and transarterial method using a "kissing microcatheter technique”. Neuroradiology 2012;54:51-59

13. Kim DJ, Kim DI, Suh SH, Byun JS, Jung JY, Kim J, et al. Vein of galen aneurysmal malformation: Treatment by transarterial venous sac and fistula embolization using coils and glue. Neurointervention 2006;1:31-34

14. Recinos PF, Rahmathulla G, Pearl M, Recinos VR, Jallo GI, Gailloud $P$, et al. Vein of galen malformations: Epidemiology, clinical presentations, management. Neurosurg Clin N Am 2012; 23:165-177

15. Lasjaunias P, Rodesch G, Terbrugge K, Pruvost P, Devictor D, Comoy J, et al. Vein of galen aneurysmal malformations. Report of 36 cases managed between 1982 and 1988. Acta Neurochir (Wien) 1989;99:26-37

16. Hamasaki T, Kai Y, Hamada J, Miura M, Kondo Y, Ushio Y. Successful treatment of a neonate with vein of galen aneurysmal malformation. Pediatr Neurosurg 2000;32:200-204

17. Watban JA, Rodesch G, Alvarez H, Lasjaunias P. Transarterial embolization of vein of galen aneurysmal malformation after unsuccessful stereotactic radiosurgery. Report of three cases. Childs Nerv Syst 1995;11:406-408

18. Payne BR, Prasad D, Steiner M, Bunge H, Steiner L. Gamma surgery for vein of galen malformations. J Neurosurg 2000;93: 229-236

19. Triffo WJ, Bourland JD, Couture DE, McMullen KP, Tatter SB, Morris PP. Definitive treatment of vein of galen aneurysmal malformation with stereotactic radiosurgery. J Neurosurg 2014; 120:120-125

20. Alvarez H, Garcia Monaco R, Rodesch G, Sachet M, Krings T, Lasjaunias P. Vein of galen aneurysmal malformations. Neuroimaging Clin N Am 2007;17:189-206

21. Levrier O, Gailloud PH, Souei M, Manera L, Brunel H, Raybaud C. Normal galenic drainage of the deep cerebral venous system in two cases of vein of galen aneurysmal malformation. Childs Nerv Syst 2004;20:91-97; discussion 98-99

22. Iizuka Y, Kakihara T, Suzuki M, Komura S, Azusawa H. Endovascular remodeling technique for vein of galen aneurysmal malformations--angiographic confirmation of a connection between the median prosencephalic vein and the deep venous system. Journal of neurosurgery. Pediatrics 2008;1:75-78 